\title{
Celiac disease and pregnancy in Indian scenario
}

\author{
Anupam Verma, Preeti Tyagi, Anu Singh* \\ Department of Obstetrics and Gynecology, L. L. R. M. Medical College, Meerut, Uttar Pradesh, India
}

Received: 10 March 2018

Accepted: 03 April 2018

\section{*Correspondence:}

Dr. Anu Singh,

E-mail: dranusingh29@gmail.com

Copyright: $\odot$ the author(s), publisher and licensee Medip Academy. This is an open-access article distributed under the terms of the Creative Commons Attribution Non-Commercial License, which permits unrestricted non-commercial use, distribution, and reproduction in any medium, provided the original work is properly cited.

\begin{abstract}
Celiac disease is a chronic lifelong inflammatory condition of gastrointestinal tract specifically the small intestine. We report a case of pregnancy outcome in a patient with celiac disease (gluten sensitive enteropathy) diagnosed during the investigations of recurrent abortions and intermittent diarrhoea since childhood. A 32 years old patient who had four abortions and loss of a premature baby was diagnosed as celiac disease during investigations of recurrent abortions and diarrhoea since childhood. After stabilisation of disease she conceived spontaneously. Patient had regular follow up in some private institute. She was referred to our hospital as a case of IUGR with color Doppler changes with breech presentation with sluggish fetal movements at 37 weeks and emergency caesarean section was performed. A male fetus with $2.25 \mathrm{~kg}$ AS 7, 9 at birth was delivered. The cause of her recurrent pregnancy losses and previous preterm birth was celiac disease. Celiac disease (CD) is an immune-mediated enteropathy caused by a permanent sensitivity to gluten in genetically susceptible individual. It may also lead to serious maternal and fetal complications because of systemic effects of disease however a successful pregnancy outcome is possible when pregestational diagnosis is made and proper management of disease during pregnancy is achieved.
\end{abstract}

Keywords: Celiac disease, Gluten enteropathy

\section{INTRODUCTION}

Celiac disease is a chronic lifelong inflammatory condition of gastrointestinal tract specifically the small intestine. ${ }^{1}$ There is increased sensitivity to gluten, an essential component of wheat and similar cereals like oats, barley, rye which contains protein gliadin.

When mucosa of small intestine is exposed to gluten, inflammation occurs, leading to loss of mucosal villi and thus the intestinal surface area significantly decreases. ${ }^{3}$

Prevalence of celiac disease is $1 \%$ globally, highest prevalence is in sub-saharan region $5.6 \%$. In India a wide gap exists between the $\mathrm{CD}$ prevalence in the population $(1 \%)$ and the prevalence based on diagnosis $(0.02 \%$ $0.27 \%$ ). Thus $90-95 \%$ of $\mathrm{CD}$ remains undetected. ${ }^{4-7} \mathrm{CD}$ is associated with a number of autoimmune and nonautoimmune conditions. There is strong evidence for the association between Type 1 diabetes and CD. ${ }^{8-19}$ Up to $8 \%$ of patients with Type 1 diabetes have the characteristic features of $\mathrm{CD}$ on small intestinal biopsy.

Systemic dental enamel defects like mixed or permanent dentition ranges from $9.5 \%$ to $95.9 \%$. Problems involving the central nervous system such as epilepsy and musculoskeletal illnesses. ${ }^{20}$ Symptoms related to reproductive system such as infertility the prevalence being $3.1 \%$ with unexplained infertility was $5.2 \%$. recurrent abortions, menstrual irregularities $.20 \%$ cases may present as primary amenorhoea. ${ }^{21}$ Females who conceive spontaneously or aided by assisted reproductive techniques show a higher rate of recurrent abortions, intra 
uterine growth restriction and pre-eclampsia in comparison to the unaffected population. ${ }^{22}$ This case report aims to discuss how celiac disease affects a Patients fertility and pregnancy outcome.

\section{CASE REPORT}

A 32-year-old female P1+4 L0 visited OPD for recurrent abortions with menstrual irregularities with diarrhea off and on and moderate anaemia. She had a pre-term female baby delivered at 7 months of gestation, who died 3 days after birth due to prematurity and had four abortions at an interval of 1 to 1.5 years, each approximately at 10 to 12 weeks of gestation, last abortion was 1 year, all were missed abortions.

Patient was thin built and after her investigations were carried out for recurrent abortions and her hormonal profile suggested of hypothyroidism and was referred to department of endocrinology and metabolism of our college (LLRM Medical College) and was admitted there for four days for proper evaluation. Patient came out with history of intermittent diarrhoea since childhood. History of ATT intake for 8 months was present 7 years back given by some local practitioner empirically because her PPD test was positive.

On examination patient was fully oriented, height 147 $\mathrm{cm}$, weight $30.4 \mathrm{~kg}$, BMI $14.07 \mathrm{~kg} / \mathrm{m} \mathrm{sq}$ (underweight). Pallor + , pedal edema + , thyroid normal on palpation, pulse and blood pressure were normal CNS, CVS, Respiratory system was normal.

\section{Investigations}

Her investigations were suggestive of moderate anemia (Hb $8.9 \mathrm{gm} / \mathrm{dl}$ ), PBF s/o mildly reduced RBC count predominantly microcytic hypochromic. She was also investigated for diabetes mellitus type 1 and for recurrent episodes of diarrhoea since childhood. Patient was found to be Anti TTG positive IgA $>136$, Anti endomysial antibody positive 1:10 titre (positive), S. TSH 4.860 mIU/L. S. Cortisol (fasting): $10.57 \mathrm{mcg} / \mathrm{dl}$, Post $250 \mathrm{mcg}$, synectin stimulation $18.76 \mathrm{mcg} / \mathrm{dl}$.

Random plasma glucose: $75 \mathrm{mg} / \mathrm{dl}$, HbA1C: 5.5 , Stool ex: normal, Usg abdomen: enlarged hyperechoic liver, edematous and dilated bowel loops with mild ascitis in pelvis. APLA was negative.

So, in view of history of anaemia, anti endomysial antibody positive, anti TTG positivity and recurrent diarrhoea since childhood final diagnosis of celiac disease was made. She was strictly kept on gluten free diet and 1-thyroxine $50 \mathrm{mcg}$.

Patient conceived spontaneously after one year of gluten free diet and had routine follow up initially in our hospital where her dose of 1-thyroxine was increased to $75 \mathrm{mcg}$ and later on to $100 \mathrm{mcg}$. Ecospirin and folic acid was started. Patient was lost to follow up till she again presented to our hospital at 37 weeks with abnormal color Doppler report with absent fetal movements with IUGR with breech presentation.

Patient underwent an emergency caesarean section. She delivered a live IUGR male baby of birth weight $2.25 \mathrm{~kg}$ with AS5, 8, liquor was scanty, and meconium stained. Patient's post-operative recovery was satisfactory and uneventful she was shifted on gluten free diet second post-operative day. She was discharged on $8^{\text {th }}$ postoperative day and was asked to follow up after 2 weeks in OPD.

\section{DISCUSSION}

Previous studies concluded that the incidence of recurrent abortions and intra uterine growth restrictions is roughly 8.9 times more in celiac sufferers. ${ }^{23}$

The immune reaction in celiac disease is towards gluten and similar proteins occurring at the mucosal lining of small intestine causing cytological damage resulting in blunting of villi due to which patient with celiac disease have gastrointestinal symptoms apart from that they have higher rates of type1 diabetes mellitus,o ral infections, recurrent abortions, intrauterine growth restriction and still births. ${ }^{24}$

Similarly, another report shows that the rate of spontaneous abortions were $15 \%$ in this group and $6 \%$ in an unaffected control group. ${ }^{25}$ Our case also presented with history of recurrent pregnancy losses. An alternative mechanism for reduced fertility may be immunemediated, possibly by compromising placental function C.D. derived IgA antibodies bonds tTG at the maternal surface of placenta and inhibits its function so CD placenta carried a high autoimmune immunoglobulin load leading to developmental and functional impairment. ${ }^{26-28}$

Mothers diagnosed with celiac disease have a higher risk of carrying intra uterine growth restricted fetus and giving birth to newborn with low birth weight basically this is related to malabsorption caused by recurrent attacks of diarrhoea, gradually resulting in malnutrition bearing this in mind Glacci et al showed that untreated celiac sufferers had higher rates of intra uterine growth restriction and low birth weight compared to those who received appropriate treatment. ${ }^{27}$ Our case also had intra uterine growth restriction and gave birth to male IUGR newborn weighing $2.25 \mathrm{~kg}$.

Another notable point is that patients of celiac disease have and increased Incidence of preterm births it is thought that increased circulatory anti glial and anti endomysial antibodies secreted as a result of autoimmune response may be the prime causative of pre-term contractions. $^{28} \mathrm{~A}$ retrospective study performed in Scandinavia reports the rate of pre term births (before 38 
weeks) in patients diagnosed with celiac disease as $6.4 \% .^{29}$

In the present case patient had a previous pregnancy loss due to pre-term birth 6 years back. Her present pregnancy was terminated by emergency caessarean section done at 37 weeks in view of abnormal BPP with absent fetal movements with $\mathrm{BOH}$.

As celiac disease is a malabsorption syndrome it is crucial for these patients to receive adequate nutrition in ante natal period. Researches show deficiency of certain trace elements and vitamins leading to pregnancy complications. ${ }^{30}$ Zinc deficiency gives rise to infertility, spontaneous abortions, congenital malformations, abruptio placentae, still birth, pre-eclampsia. ${ }^{31}$

Iron deficiency leads to increased rate of fetomaternal morbidity and folate deficiency leads to congenital malformations. ${ }^{32}$ Patient took Iron and folic acid supplementation regularly however still had anemia due to malabsorption.

\section{CONCLUSION}

In Indian scenario most of the patients of celiac disease remain undiagnosed. Although it is due gluten sensitivity which is found in wheat, rye, barley, oats, resulting in inflammation of mucosa of small intestine. Patient have a wide spectrum of disorders which include systemic dental enamel defects, problems involving CNS like epilepsy musculoskeletal disorders, it also leads to unexplained infertility, recurrent abortions, pre-term labour, pre-term births, intra uterine growth restriction and pre-eclampsia.

In the present case the patient had recurrent pregnancy losses and intermittent diarrhea since childhood. However, with strict gluten free diet and appropriate management a successful pregnancy outcome may be achieved

\section{Funding: No funding sources \\ Conflict of interest: None declared \\ Ethical approval: Not required}

\section{REFERENCES}

1. Danowski L, Brand LG, Connolly J. Selections from Current Literature: gluten-free diets, coeliac disease and associated disorders. Fam Pract. 2003;20:60711.

2. Hin H, Bird G, Fisher P, Mahy N, Jewell D. Coeliac disease in primary care: case finding study. BMJ 1998;318:164-7.

3. Kaukinen K, Collin P, Holm K, Karvonen AL, Pikkarainen P, Maki M. Small bowel mucosal inflama-tion in reticulin or gliadin antibody positive patients without villous atrophy. Scand J Gastroenterol. 1998;33:944-9.
4. Fasano A, Catassi C. Current approaches to diagnosis and treatment of celiac disease: an evolving spectrum. Gastroenterol. 2001;120:636-51.

5. Fasano A, Berti I, Gerarduzzi T. Prevalence celiac disease in at risk and not-at-risk groups in the United States: a large multicenter study. Arch Intern Med. 2003;163:286-92.

6. Gomez JC, Selvaggio GS, Viola M. Prevalence of celiac disease in Argentina: screening of an adult population in the La Plata area. Am J Gastroenterol. 2001;96:2700-4.

7. Rewers M. Epidemiology of celiac disease: what are the prevalence, incidence, and progression of celiac disease? Gastroenterol. 2005;128(4)(1):S47-51.

8. Acerini CL, Ahmed ML, Ross KM, Sullivan PB, Bird G, Dungar DB. Coeliac disease in children and adolescents with IDDM: clinical characteristics and response to gluten-free diet. Diabet Med. 1998;15:38-44.

9. Carlsson A, Axelsson I, Borulf S. Prevalence of IgAantiendomysium and IgA-antigliadin autoantibodies at diagnosis of insulin dependent diabetes mellitus in Swedish children and adolescents. Pediatr. 1999; 103:1248-52

10. Cronin CC, Feighery A, Ferriss JB, Liddy C, Shanahan F, Feighery C. High prevalence of celiac disease among patients with insulin-dependent (type 1) diabetes mellitus. Am J Gastroenterol. 1997;92:2210-2.

11. Fraser-Reynolds K, Butzner J, Stephure D, Trussell R, Scott RB. Use of immunoglobulin: a antiendomysial antibody to screen for celiac disease in North American children with type 1 diabetes. Diabetes Care. 1998;21:1985-9.

12. Gillett PM, Gillett HR, Israel DM. High prevalence of celiac disease in patient with type 1 diabetes detected by antibodies to endomysium and tissue transglutaminase. Can J Gastroenterol. 2001;15:297301.

13. Koletzko S, Burgin-Wolff A, Koletzko B. Prevalence of coeliac disease in diabetic children and adolescents: a multicenter study. Eur J Pediatr 1988;148:113-7.

14. Maki M, Huupponen T, Holm K, Hallstrom O. Seroconversion of reticulin autoantibodies predicts coeliac disease in insulin de-pendent diabetes mellitus. Gut. 1995;36:239-42.

15. Saukkonen T, Savilahti E, Reijonen H, Ilonen I, Tuomilehto-Wolf G, Akerblom HK. Coeliac disease: frequent occurrence after clinical onset of insulin dependent childhood diabetes in Finland Study Group. Diabet Med. 1996;13:464-70.

16. Savilahti E, Simell O, Kroskimies S, Rilva A, Akerblom HK. Celiac disease in insulin-dependent diabetes mellitus. J Pediatr. 1986;108:690-3.

17. Schober E, Bittman b, Granditsch G, et al. Screening by antiendomysium antibody for celiac disease in diabetic children and adolescents in Austria. J Pediatr Gastroenterol Nutr. 2000;30:391-6. 
18. Sigurs N, Johansson C, Elfstrand P, Viander M, Lanner A. Prevalence of celiac disease in diabetic children in adolescents in Sweden. Acta Paediatr. 1993;82:748-51.

19. Hoffenberg EJ, Bao F, Eisenbarth GS. Transglutaminase antibodies in children with a genetic risk for celiac disease. J Pediatr. 2000;137(3):356-60.

20. Troncone R, Greco L, Auricchio S. Gluten sensitive entheropathy. Pediatr Clin North Am. 1996;43:35573.

21. Sher KS, Mayberry JF. Female fertility, obstetrics and gynaecological history in coeliac disease: a case control study. Digestion. 1994;55:243-6.

22. Martinelli P, Tronce R, Paparo F. Coeliac disease and unfavourable outcome of pregnancy. Gut. 2000;46:332-5.

23. Ciacci C, Cirillo M, Auriemma G. Celiac disease and pregnancy outcome. Am J Gastroenterol. 1996;91:718-22.

24. King LA, Ciclitira PJ. Celiac disease. Current Opinion Gastroenterol. 2000;16:102-6.

25. Martinelli P, Tronce R, Paparo F. Coeliac disease and unfavourable outcome of pregnancy. Gut. 2000;46:332-5.

26. Anjum N, Baker PN, Robinson NJ, Aplin JD. Maternal celiac disease autoantibodies bind directly to syncytiotrophoblast and inhibit placental tissue transglutaminase activity. Reprod Biol Endocrinol. 2009;7:16.

27. Ciacci C, Cirillo M, Auriemma G. Celiac disease and pregnancy outcome. Am J Gastroenterol. 1996;91:718-22.

28. Rostami K, Steegers EAP, Wong WY, Braat DD, Steegers-Theunissen RPM. Coeliac disease and reproductive dis-orders: a neglected association. Eur J Obstet Gynecol Reprod Biol. 2001;96:146-9.

29. Ludvigsson JF, Montgomery SM, Ekbom A. Coeliac disease in the father and risk of adverse pregnancy outcome: a population-based cohort study. Scand J Gastroenterol. 2006;41:178-85.

30. Bougle D, Proust A. Iron and zinc supplementation during pregnancy: interactions and requirements. Contracept Fertil Steril. 1999;27:537-43.

31. Seibel MM. The role of nutrition and nutritional supplements in women's health. Fertil Steril. 1999;72:579-91.

32. Nelen WLDM, Blom HJ, Steegers EAP. Homocystein and folate levels as risk factors for recurrent early pregnancy loss. Obstet Gynecol. 2000;95:519-24.

Cite this article as: Verma $\mathrm{A}$, Tyagi $\mathrm{P}$, Singh $\mathrm{A}$.

Celiac disease and pregnancy in Indian scenario. Int $\mathbf{J}$ Reprod Contracept Obstet Gynecol 2018;7:2065-8. 